\title{
Analysis of masonry arches reinforced with FRP sheets: experimental results and numerical evaluations
}

\author{
Stefano Galassi ${ }^{1, a}$ \\ ${ }^{1}$ Department of Architecture, University of Florence, Italy
}

\begin{abstract}
In recent years fiber-reinforced polymers (FRP) have been widely used for strengthening masonry structures. In particular, in the case of masonry arches, the use of FRP sheets increases load-bearing capacity by limiting or preventing the occurrence of tensile cracks that could activate collapse mechanisms. The effectiveness of the strengthening intervention depends on the bond between FRP and substrate, due to the shear and normal stresses that occur in the bond interface, so much so that the typical failure mode of an arch reinforced with narrow FRP sheets at the intrados is exactly delamination. In this paper a predictive numerical procedure of the combined mode I and mode II failure is proposed. Numerical results provided by this procedure are compared to the experimental results on in-scale arch models taken from a recent work of the author.
\end{abstract}

\section{Introduction}

The need for preserving, restoring and consolidating architectural and monumental heritage [1, 2], as well as ruins in archaeological sites [3-6], is the reason for the development of innovative materials and techniques for strengthening and repairing them [7-14]. In this framework, masonry arches, vaults and domes are typical and recurrent structural elements of architectural heritage that need to be preserved. For the analysis of these types of structures, new numerical tools [15-27] have been recently presented.

A very widespread technique for consolidating and retrofitting masonry structures is the use of fiberreinforced polymer sheets (FRP) bonded to the substrate by an adhesive layer (often an epoxy matrix). In order to effectively increase the load carrying capacity and the ductility of FRP bonded joints mechanical anchors can also be used [28, 29]. The main reason for the success of the strengthening intervention using FRP materials is due to their compatibility with masonry [30] as well as other advantages that they allow, compared to traditional materials and techniques, such as lightness, high resistance, high elastic modulus and stiffness and rapid installment in the structure.

However, the effectiveness of the reinforcement intervention strongly depends on the bond performance between FRP and substrate. In the bond interface shear and normal stresses (i.e. adhesion and peeling forces) are generated during load transfer from the masonry to the reinforcement. The peeling forces, that are provoked due to the curved shape of the arch, are tension if the reinforcement is placed at the intrados. The combination of peeling and shear forces are responsible for the typical

\footnotetext{
a Corresponding author: stefano.galassi@unifi.it
}

delamination failure, that is the detachment of the sheet from the masonry. Experimental investigations have shown that, unlike FRCM composites in which failure occurs exactly in the fiber-matrix interface [31-33], in FRPs failure occurs at the composite-substrate interface affecting the superficial layer of the masonry [34-39], due to the higher strength of the adhesive as respect to that of masonry.

In this paper a novel mechanical model of an arch reinforced with intrados FRP sheets is presented and a non-linear numerical procedure for investigating the bond behaviour is also proposed. The algorithm checks the shear and peeling forces in the bond interfaces and monitors the full delamination process, step by step, during the increase of an external load.

\section{Reinforced arch model}

Two main failure modes are considered: the occurrence of cracks in the mortar joints due to tensile forces and the delamination of the sheet from the substrate due to peeling and adhesion forces in the bond interfaces. In order to address both failure modes, the FRP reinforced arch (Fig. 1a) is modeled as follows. The masonry arch is composed of $n$ rigid-blocks assembled by elastic mortar joints. In the mortar joints, all the elasticity (i.e.: deformability) of the arch is concentrated. Each mortar joint is, in turn, represented by a device composed of four links orthogonal to the mid-surface of the joint, plus an additional link arranged along that surface (hereafter referred to as tangential link).

The reinforcement is represented through $n+1$ additional links, placed at the intrados of the arch. Such 
links connect, in series, the midpoints of the intrados of adjacent blocks.

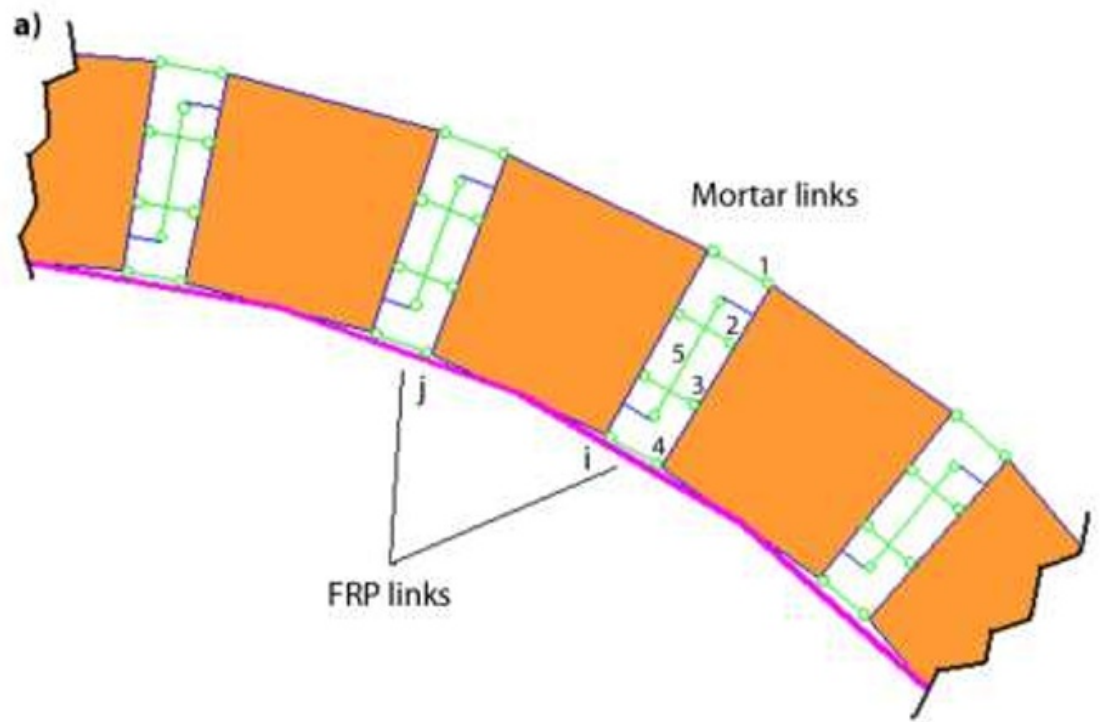

and $\alpha_{\mathrm{j}}$ the slope of these vectors. $\overline{\mathrm{X}}_{\mathrm{t}}$ is the threshold value of the mortar tensile force in the generic link and $\bar{X}_{\text {bond }}$ is

b)

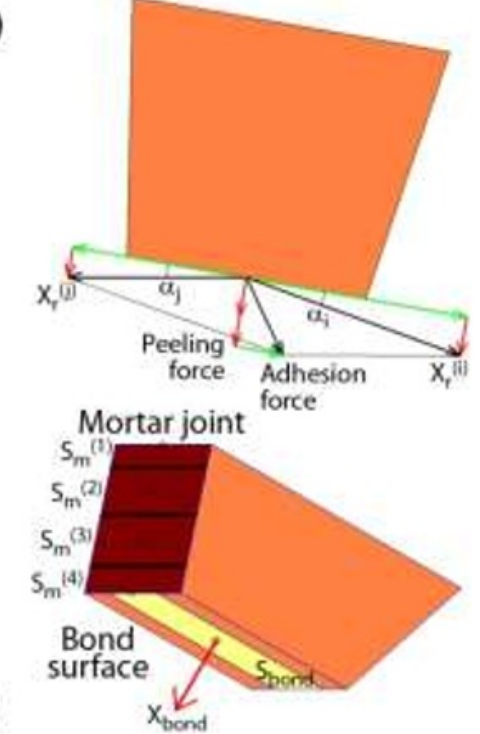

Figure 1. a) The reinforced arch model; b) Decomposition of the FRP link axial forces into the adhesion and peeling forces; c) Peeling force and bond surface in the generic arch block; area of the axial links in a mortar joint.

The links orthogonal to the mid-surface of the mortar joints measure the axial force. If the axial force is a tension higher than the tensile strength of mortar, the corresponding link fails and a crack occurs. Instead, the tangential link that measures the shearing force in the mortar joint is considered to be infinitely rigid and strong, in order to avoid sliding joints. As for the bond behaviour between FRP and masonry, each couple of reinforcement links ( $i$ and $j$ in Fig. 1a) provides, at the intrados midpoint of the generic block of the arch, a resultant force directed towards the centre of the arch, whose components measure both the adhesion and peeling forces (Fig. 1b). If such forces exceed the tensile strength of masonry, delamination occurs and, in the mechanical model, links $i$ and $j$ are substituted by a new reinforcement link that connects the midpoint (start node of link $i$ ) of the previous block to the midpoint (end node of link $j$ ) of the next one.

\section{Solution algorithm}

The two failure criteria formulated above are represented by Eq. (1), Fig. 1b,c:

$$
\begin{gathered}
\left\{\begin{array}{c}
\mathrm{X}_{\mathrm{t}} \leq \overline{\mathrm{X}}_{\mathrm{t}} \\
\mathrm{X}_{\text {bond }}=\mathrm{X}_{\mathrm{r}}^{(\mathrm{i})} \sin \alpha_{\mathrm{i}}+\mathrm{X}_{\mathrm{r}}^{(\mathrm{j})} \sin \alpha_{\mathrm{j}} \leq \overline{\mathrm{X}}_{\text {bond }}
\end{array}\right. \\
\text { with }\left\{\begin{array}{c}
\overline{\mathrm{X}}_{\mathrm{t}}=\mathrm{S}_{\mathrm{m}} \cdot \bar{\sigma}_{\mathrm{t}}^{(\mathrm{m})} \\
\overline{\mathrm{X}}_{\text {bond }}=\mathrm{S}_{\text {bond }} \cdot \bar{\sigma}_{\mathrm{t}}^{(\mathrm{b})}
\end{array}\right.
\end{gathered}
$$

where $X_{t}$ is the tensile force in a specific link orthogonal to a mortar joint, $X_{r}^{(i)}$ and $X_{r}^{(j)}$ the axial forces in the couple of external links that simulate the intrados reinforcement in correspondence to a generic block, $\alpha_{i}$ the debonding force (herein assumed to be coincident with the peeling force, Fig. 1c). $\bar{X}_{t}$ and $\bar{X}_{\text {bond }}$ are computed by multiplying the tensile strength of mortar $\bar{\sigma}_{t}^{(m)}$ by the cross sectional area of the axial link $S_{m}$ and the tensile strength of the block $\bar{\sigma}_{t}^{(b)}$ by the bond surface $S_{\text {bond }}$ under the generic block respectively.

To perform the analysis of the reinforced rigid block arch, the equilibrium equation and the elastic-kinematic equation are formulated in Eq. 2 in matrix form:

$$
\left\{\begin{array}{c}
\mathrm{AX}=\lambda \mathrm{F} \\
\widetilde{\mathrm{A}} \mathrm{x}+\mathrm{KX}=\Delta
\end{array}\right.
$$

where $\{F\}$ is the vector of the loads and $\lambda$ the incremental load factor, $\{\mathrm{X}\}$ is the vector of the unknown forces in the links of the mortar and FRP joints, [A] is the equilibrium matrix, $\{\mathrm{X}\}$ is the vector of the displacements of the block centroids and $[\mathrm{K}]$ is the matrix whose entries are the deformability of mortar and FRP links. Vector $\{\Delta\}$, the "impressed distortion vector", is used to simulate, in the model, the mortar tensile failure, i.e. the failure of some links orthogonal to the joint.

Eq. 3 is the solution of Eq. 2, that provides the forces both in the mortar and FRP links. At the beginning of the analysis, vector $\{\Delta\}=\{0\}$ because the masonry arch and the reinforcement are assumed to be undamaged when values of $\lambda$ are low:

$$
X=K^{-1} \widetilde{A}\left(A K^{-1} \widetilde{A}\right)^{-1} \cdot \lambda F+\left(I-K^{-1} \widetilde{A}\left(A K^{-1} \widetilde{A}\right)^{-1} A\right) \cdot \Delta(3)
$$

During the analysis, the value of $\lambda$ is slowly increased and, in correspondence to each value of $\lambda$, the two failure criteria in Eq. (1) are checked. According to Eq. (1), the algorithm introduces a distortion coefficient [40] in the mortar link whose force, at the current step of the incremental analysis, does not respect the first of the inequalities in Eq. (1). The distortion provokes the failure of that link. Instead, as for the debonding failure of the reinforcement, it occurs when the second of Eq. 1 is not respected, in which $\bar{X}_{\text {bond }}$ is computed considering the 
strength of masonry, where the failure occurs (ripping), rather than the strength of the adhesive. Delamination is simulated by changing the reinforcement pattern as described in the previous section, without introducing further distortion coefficients in the numerical model.

At the end of the incremental nonlinear analysis, both the value of the load factor $\lambda$ and the failure mode of the arch are captured.

\section{Experimental evidence and numerical results}

In the experimental campaign performed in [39] on in scale 1:2 models of masonry arches reinforced with FRP composite materials at the intrados, it was observed that the tested specimens with narrow FRP sheets failed due to delamination of the reinforcement, while specimens reinforced with wider sheets failed due to sliding blocks and/or masonry crushing.

Such models reproduced a segmental arch with a 150 $\mathrm{cm}$ spam, an internal radius corresponding to $86.5 \mathrm{~cm}$, with fixed imposts and inclined by $30^{\circ}$ and a $10 \times 10 \mathrm{~cm}$ square cross section.

The experimental trial took place by impressing an increasing vertical displacement at the keystone using a hydraulic jack. In correspondence to a load of $1.98 \mathrm{kN}$ the first crack at the keystone appeared and then, later, at a load of $2.63 \mathrm{kN}$ at the haunches. In correspondence to a load of $4.32 \mathrm{kN}$ the delamination process occurred, and, starting from the keystone sections this process was enlarged little by little to the sections near the left haunch taking away part of the masonry (Fig. 2).
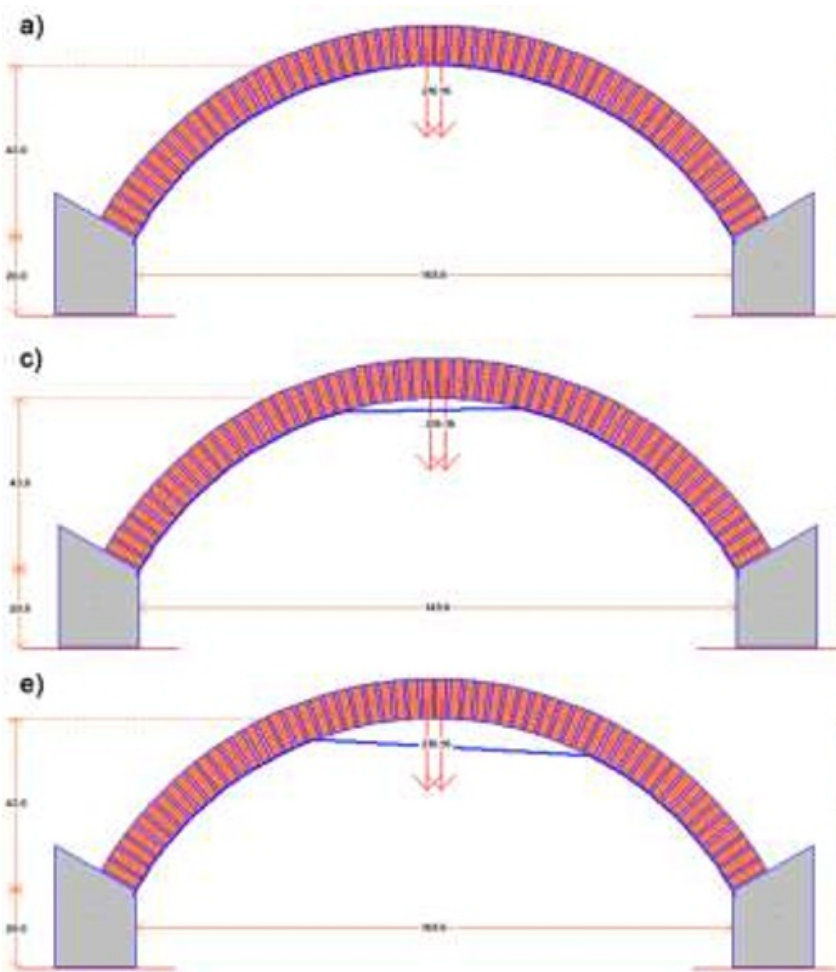

Figure 3. Delamination process computed by the proposed algorithm. (Taken from [39]).

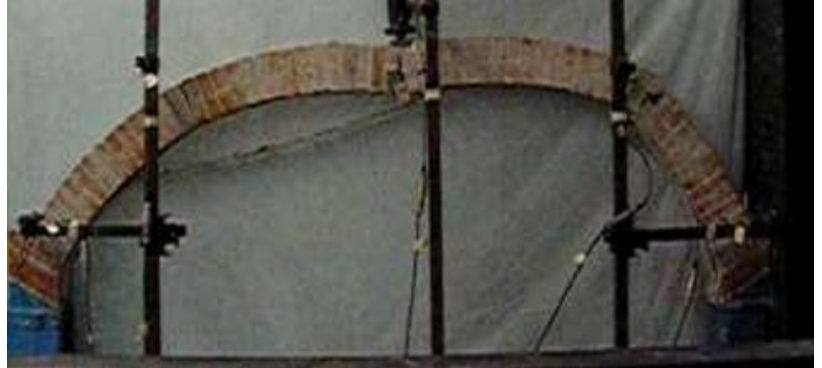

Figure 2. Experimental trial. (Taken from [39]).

In the numerical model the action of the hydraulic jack at the keystone of the arch was simulated by inputting two equal point forces at the centre of gravity of both the keystone blocks. During the analysis, these forces were slowly increased.

The numerical model showed (Fig. 3), step by step, the delamination process which also occurred in the laboratory. It highlighted a peak load of the same level as the one achieved experimentally as well as the cracking pattern, which shows the failure of mortar joints due to tensile forces, and also the position of the sheet detached from many intrados interfaces. It is worth noting that the configuration drawn by the computer program, in which the numerical procedure is implemented, is the mirror image of that obtained in the laboratory.

\section{Conclusions}

In this paper a mechanical model and the related numerical procedure for the analysis of masonry arches reinforced with FRP sheets at the intrados, has been
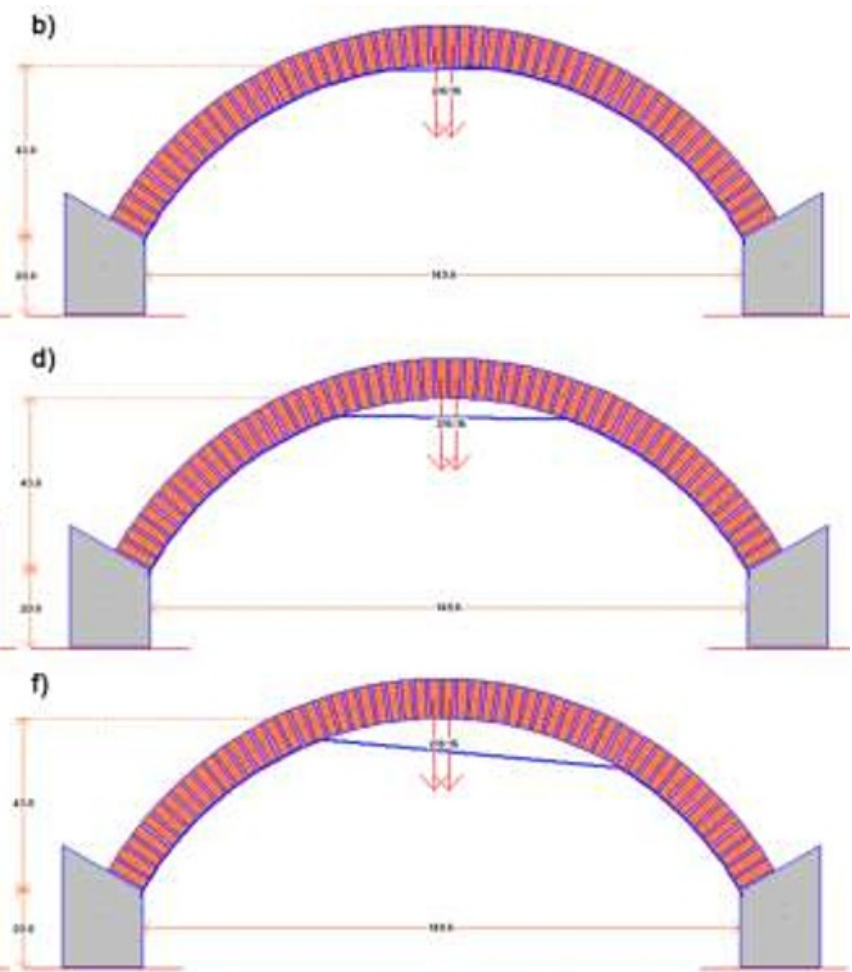

presented.

Even if a reinforced arch can fail in different ways, the delamination of the reinforcement from the arch that, 
generally, follows or occurs simultaneously to a phase of micro-cracking in the mortar joints due to tensile forces, is herein proposed to be assumed as the reference failure mode for designing the reinforcement intervention. Indeed, according to the strength hierarchy criterion, the failure due to delamination is more preferable to masonry crushing, which spoils the structure without any remedy, and also to FRP rupture, that causes the arch to collapse almost immediately.

Therefore, the numerical procedure discussed in this paper is proposed in order to provide guidance for designing a targeted reinforcement system in order to avoid undesirable failure modes.

The agreement between numerical results and the results of the experimental arches tested in the laboratory confirms the reliability of the proposed procedure.

\section{Acknowledgments}

The author wishes to thank Architect Daniela Sinicropi, that performed the experimental trial in our Laboratory.

\section{References}

1. S. Galassi, L. Dipasquale, N. Ruggieri, G. Tempesta, Andalusian timber roof structure in Chefchaouen, Northern Morocco: construction technique and structural behavior, J. Archit. Eng. 24, 3, 04018012 (2018) 10.1061/(ASCE)AE.1943-5568.0000315

2. M. Paradiso, S. Galassi, S. Benedetti, Il caratteristico Forte di San Fernando de Bocachica, Colombia, in: Luis Villegas, Ignacio lombillo, Clara Liano, Haydee Blanco (Eds.), Patologia della Costruccion, Tecnologia de la Rehabilitacion y Gestion del Patrimonio, Proc. Conf. Latinoamericano Patologie del costruito, tecniche di riabilitazione e gestione del patrimonio (Rehabend 2014), Santander, Spain, Gráficas Iguña, S.A. (2014)

3. N. Ruggieri, S. Galassi, G. Tempesta, Pompeii's Stabian Baths. Mechanical behaviour assessment of selected masonry structures during the 1st century seismic events, Int. J. Archit. Herit. 12, 5, 859-878 (2018) 10.1080/15583058.2017.1422571

4. M. Sassu, M. Andreini, C. Casapulla, A. De Falco, Archaeological consolidation of UNESCO masonry structures in Oman: The Sumhuram citadel of Khor Rori and the Al Balid Fortress, Int. J. Archit. Herit. 7,4, 339-374 (2013)

5. R. Aguilar, R. Marques, K. Sovero, C. Martel, F. Trujillano, R. Boroschek, Investigations on the structural behaviour of archaeological heritage in Peru: From survey to seismic assessment, Eng. Struct. 95, 94-111 (2015)

6. A. Albuerne, M. S. Williams, Structural appraisal of a Roman concrete vaulted monument: the Basilica of Maxentius, Int. J. Archit. Herit. 11,7, 901-912 (2017)

7. M. Paradiso, S. Galassi, A. Borri, D. Sinicropi, "Reticolatus": an innovative reinforcement for irregular masonry. A numeric model, in: Paulo J. S. Cruz (Ed.), Structures and Architecture: Concepts, Applications and Challenges, CRC Press / Balkema,
Taylor and Francis Group, London, Proc. 2nd Int. Conf. on Structure \& Architecture ICSA2013, Guimaraes, Portugal (2013)

8. V. Alecci, F. Focacci, L. Rovero, G. Stipo, M. De Stefano, Intrados strengthening of brick masonry arches with PBO-FRCM composites: experimental and analytical investigations, Compos. Struct. 176, 898-909, (2017) 10.1016/j.compstruct.2017.06.023

9. V. Alecci, M. De Stefano, F. Focacci, R. Luciano, L. Rovero, G. Stipo, Strengthening masonry arches with lime-based mortar composite, Buildings 7, 2, 49 (2017) 10.3390/buildings7020049

10. M. Fagone, G. Ranocchiai, An Experimental Analysis of the Mechanical Behaviour of Anchored CFRP-to-Masonry Reinforcements Loaded by Outof-Plane Actions, Key Eng. Mat. 747, 204-11 (2017) 10.4028/www.scientific.net/KEM.747.204

11. L. Jurina, Experimental tests on consolidation of masonry bridges using "ram-reinforced arch method", Proc. IIX International Conference on Arch Bridges, 5-7 October 2016, Wroclaw, Poland (2016)

12. A. Borri, G. Castori, M. Corradi, Intrados strengthening of brick masonry arches with composite materials, Compos. Part B-Eng. 42, 5, 1164-1172 (2011)

13. M. Corradi, A. Borri, G. Castori, R. Sisti, The Reticulatus method for shear strengthening of fairfaced masonry, Bulletin of Earthquake Engineering 14, 12, 3547-3571 (2016) 10.1007/s10518-0160006-5

14. G. Castori, A. Borri, M. Corradi, Behavior of thin masonry arches repaired using composite materials, Compos. Part B-Eng. 87, 311-321 (2016) 10.1016/j.compositesb.2015.09.008

15. S. Galassi, G. Misseri, L. Rovero, G. Tempesta, Equilibrium analysis of masonry domes. On the analytical interpretation of the Eddy-Lévy graphical method, Int. J. Archit. Herit. 11, 8, 1195-1211 (2017) 10.1080/15583058.2017.1372823

16. S. Galassi, G. Tempesta, Analysis of Masonry Block Structures with Unilateral Frictional Joints, in: Proc. Int. Conf. on Electronic, Control, Automation and Mechanical Engineering (ECAME 2017), 19-20 November 2017, Sanya, China, DEStech Transactions on Engineering and Technology Research, 246-51, 10.12783/dtetr/ecame2017/18396

17. F. Pugi, S. Galassi, 2013 Seismic analysis of masonry voussoir arches according to the Italian building code, Ing. Sismica-Ital. 30 ,3, 33-55 (2013)

18. M. Paradiso, S. Galassi, S. Benedetti, Stabilità di archi e volte in muratura: metodi tradizionali e calcolo automatico, in: Luis Villegas, Ignacio lombillo, Clara Liano, Haydee Blanco (Eds.), Patologia della Costruccion, Tecnologia de la Rehabilitacion y Gestion del Patrimonio, Proc. Conf Latinoamericano Patologie del costruito, tecniche di riabilitazione e gestione del patrimonio (Rehabend 2014), Santander, Spain, Gráficas Iguña, S.A. (2014)

19. V. Alecci, M. De Stefano, S. Galassi, M. Lapi, M. Orlando, An assessment of American criterion for detecting plan irregularity, in: Proc. of Eighth European Workshop on the Seismic Behaviour of 
Irregular and Complex Structures (8EWICS), 19-20 October 2017, Bucharest, Romania (2017)

20. S. Briccoli Bati, M. Fagone, T. Rotunno, Lower Bound Limit Analysis of Masonry Arches with CFRP Reinforcements: A Numerical Method, J. Compos. Constr. 17, $366 \quad$ (2013) 10.1061/(asce)cc.1943-5614.0000350

21. A. Caporale, R. Luciano, L. Rosati, Limit analysis of masonry arches with externally bonded FRP reinforcements, Comput. Method Appl. M. 196, 247260 (2006)

22. S. Galassi, N. Ruggieri, G. Tempesta, A novel numerical tool for seismic vulnerability analysis of ruins in archaeological sites, Int. J. Archit. Herit. (2018), 10.1080/15583058.2018.1492647

23. S. Galassi, G. Misseri, L. Rovero, G. Tempesta, Failure modes prediction of masonry coussoir arches on moving supports, Eng. Struct. 173, 706-717 (2018) 10.1016/j.engstruct.2018.07.015

24. S. Galassi, M. Paradiso, BrickWORK SoftwareAided Analysis of Masonry Structures, IERI Procedia 7, 62-70 (2014), Special Issue 2013 International Conference on Applied Computing, Computer Science, and Computer Engineering (ICACC 2013), USA, December 2013, Elsevier B.V., ISSN: 2212-6678, 10.1016/j.ieri.2014.08.011

25. G. Salerno, How to recognize the order of infinitesimal mechanisms: A numerical approach, International Journal for Numerical Methods in Engineering 35, 7, 1351-1395 (1992) 10.1002/nme. 1620350702

26. G. Salerno, A. Billotta, F. Porco, A finite element with micro-scale effects for the linear analysis of masonry brickwork, Comput. Methods Appl. Mech. Eng. 190, 34, 4365-4378 (2001) 10.1016/S00457825(01)00165-7

27. G. Uva, G. Salerno, Towards a multiscale analysis of periodic masonry brickwork: A FEM algorithm with damage and friction, Int. J. Solids Struct. 43, 13, 3739-3769 (2006) 10.1016/j.ijsolstr.2005.10.004

28. S. Briccoli Bati, M. Fagone, G. Ranocchiai, The effects of mortar joints on the efficiency of anchored CFRP sheets reinforcements of brick-masonry, Key Eng. Mater. 624, 575-83 (2015) 10.4028/www.scientific.net/KEM.624.575

29. Fagone M, Ranocchiai G, Briccoli Bati S. An experimental analysis about the effects of mortar joints on the efficiency of anchored CFRP-tomasonry reinforcements, Compos. Part B-Eng. 76, 133-48 (2015) 10.1016/j.compositesb.2015.01.050

30. D. Sinicropi, E. Perria, S. Galassi, M. Paradiso, A. Borri, Artificial Ageing of Mortar Prisms Reinforced through Steel, Glass and Organic Fibers, Journal of Key Eng. Mat., A. Di Tommaso, C. Gentilini and G. Castellazzi (Eds.) 624, 4, 542-50 (2014) 10.4028/www.scientific.net/KEM.624.542

31. V. Alecci, M. De Stefano, R. Luciano, L. Rovero, G. Stipo, Experimental Investigation on Bond Behavior of Cement-Matrix-Based Composites for Strengthening of Masonry Structures, J. Compos. Constr. 20, 1 (2016)
32. C. Pellegrino, T. D’Antino, Experimental behaviour of existing precast prestressed reinforced concrete elements strengthened with cementitious composites, Compos. Part B-Eng. 55, 31-40 (2013)

33. V. Alecci, S. Briccoli Bati, G. Ranocchiai, Concrete columns confined with CFRP wraps, Mater. Struct. Constr. 47, 3, 397-410 (2014) 10.1617/s11527-0130068-7

34. H. Yuan, J.C. Teng, R. Seracini, Z.S. Wu, J. Yao, Full-range behavior of FRP-to-concrete bonded joints, Eng. Struct. 26, 553-65 (2004)

35. M.R. Valluzzi et al., Round robin test for compositeto-brick shear bond characerization. Mater. Struct. 45, 12, 1761-91 (2012)

36. L. Rovero, F. Focacci, G. Stipo, Structural behavior of arch models strengthened using FRP strips of different lengths, J. Compos. Constr. 17, 2, 249-58 (2013) 10.1061/(ASCE)CC.1943-5614.0000325

37. T. Rotunno, L. Rovero, U. Tonietti, S. Briccoli Bati, Experimental study of bond behavior of CFRP-tobrick joints, J. Compos. Constr. 04014063 (2015) 10.1061/(ASCE)CC.1943-5614.0000528

38. S. Briccoli Bati, L. Rovero, Towards a methodology for estimating strength and collapse mechanism in masonry arches strengthened with fibre reinforced polymer applied on external surfaces, Mater. Struct. 41, 7, 1291-1306 (2008)

39. S. Galassi, A numerical procedure for failure mode detection of masonry arches reinforced with fiber reinforced polymeric materials, IOP Conf. Ser.: Mater. Sci. Eng. 369, 012038 (2018) 10.1088/1757899X/369/1/012038, Proc. of 5th Global Conference on Polymer and Composite Materials (PCM 2018) (10-13 April 2018, Kitakyushu City, Japan)

40. G. Colonnetti, Scienza delle Costruzioni (Edizioni Scientifiche Einaudi, Torino, 1955) 